\title{
SYMBIOTIC MYCORRHIZAL FUNGI ISOLATED VIA EX SITU SEED BAITING INDUCE SEED GERMINATION OF DENDROBIUM CATENATUM LINDL. (ORCHIDACEAE)
}

\author{
SHAO, S.-C. - XI, H.-P. - MOHANDASS, D.* \\ Gardening and Horticulture Department, Xishuangbanna Tropical Botanical Garden, Chinese \\ Academy of Sciences, Mengla County, Yunnan 666303, P. R. China \\ *Corresponding author \\ e-mail: dmohandass997@yahoo.com \\ (Received 20 $0^{\text {th }}$ Mar 2019; accepted 24 ${ }^{\text {th }}$ May 2019)
}

\begin{abstract}
The epiphytic orchid species Dendrobium catenatum is extensively used as a traditional medicine in China. Overexploitation has led to endangerment and rarity of the species in the wild, and conservation measures are immediately needed. As in many orchid species, mycorrhizal symbiotic seed germination is recognized as a powerful tool for orchid seedling propagation, reintroduction, and species conservation. Obtaining efficient and specific fungi for enhancing seed germination, protocorm formation, and further seedling development is a prerequisite. In this study, eight purified fungal strains were isolated from host orchid protocorms via an ex situ baiting technique. Phylogenetic analysis using ITS-rDNA placed the eight fungal strains into the taxa Tulasnellaceae, Ceratobasidiaceae, and Sebacinales, the typical orchid mycorrhizal symbionts. The fungi induced seed germination and also increased growth during protocorm formation, seedling formation, and seedling development. One strain in particular (SSCDO-5) exhibited significant benefits under 12/12 h light/dark conditions between 20 and 90 days after sowing. Our results suggest that inoculation with the fungus SSCDO-5 might assist in the propagation of $D$. catenatum and could be employed ex situ and in situ for conservation purposes.
\end{abstract}

Keywords: conservation effort, photoperiod, reintroduction, seedling development, Tulasnellaceae

\section{Introduction}

Symbiotic fungi play an important role in the orchid life cycle, from seed germination, through protocorm formation to seedling development, and even into adulthood when they provide nutrition supplemental to photosynthesis (Selosse and Roy, 2009). Mycorrhizal studies are essential and necessary to ensure success in propagation from seeds and to benefit integrated orchid conservation. Highly compatible symbiotic fungi can play a major role in the initiation of seed germination and recruitment of Orchidaceae (Park and Lee, 2013; Rasmussen et al., 2015; Khamchatra et al., 2016; Huang et al., 2018). The isolation, identification, and culture of germination-enhancing fungi are prerequisites for symbiotic seed germination and seedling growth.

Most studies have focused on screening fungi effective in promoting seed germination, mainly using different strains acquired from roots (Johnson et al., 2007; Stewart and Kane, 2007; Chutima et al., 2011; Wu et al., 2012; Fracchia et al., 2016). Among these, 14 fungi isolates from the roots of 10 species were assessed in terms of germination percentage of Cynorkis purpurea seeds, which displayed low specificity for germination in vitro (Rafter et al., 2016). However, only a few studies have examined epiphytic orchids using in situ baiting techniques applied to seed germination in association with symbiotic mycorrhizal fungi (Wang et al., 2011; Zi et al., 2014; Zhou and Gao, 2016). Herrera et al. (2016) found that 13 mycorrhizal isolates from 7 hosts 
had the ability to induce seed germination with various efficiencies and low specificity in vitro. Wu et al. (2012) inoculated seeds of Dendrobium catenatum with four symbiotic fungi in vitro (strains C20 from D. catenatum and L12, L24b, and L28 from D. loddigesii) and found that strains L24b and L28 had significantly higher germination rates, but the seeds did not form seedlings. Two Tulasnella strains isolated from roots of an endangered species, $D$. nobile, differed in their ability to facilitate germination and subsequent development in D. officinale ( $=$ D. catenatum) in vitro (Tan et al., 2014). Swangmaneecharern et al. (2012) found that four out of five fungal strains from other genera could form pelotons in Dendrobium spp.

Although it is more convenient to isolate symbiotic fungi from roots to screen for effective species in vitro, this approach is biased toward specificity under experimental conditions and not necessarily those pertaining in the field where the ecological conditions are more specific (Masuhara and Katsuya, 1994; Steinfort et al., 2010). Masuhara and Katsuya also found that most Rhizoctonia spp. not associated with the in situ germination of Spiranthes sinensis var. amoena induced seed germination in vitro, demonstrating differences in seed specificity according to conditions (Masuhara and Katsuya, 1994). Based on this characteristic, Rasmussen et al., (2015) suggested that non-compatible fungi may stimulate germination per se, but are not necessary to support subsequent seedling development. Other authors have also agreed that the orchidfungus relationship is not the same in in situ and in vitro conditions ( $\mathrm{Zi}$ et al., 2014; Cruz-Higareda et al., 2015). The use of germination-promoting fungi isolated from protocorms in situ/ex situ of the same species can ensure high compatibility and adaptation between orchid species and fungal partners and thus support restoration efforts and orchid conservation (Zi et al., 2014; Shao et al., 2017; Huang et al., 2018).

However, it is difficult to gather protocorms in the wild because they are very small and sparsely distributed. The use of in situ and ex situ baiting methods has been proposed to overcome such problems and ensure effective protocorm sampling (Rasmussen and Whigham, 1993; Brundrett et al., 2003). The ex situ baiting method allows close observation of the germination process, and provides time for choosing the optimum stage for mycorrhizal fungus isolation. $\mathrm{Xu}$ and Guo (1989) isolated an effective symbiotic fungus, Mycena osmundicola, from protocorms of Gastrodia elata by ex situ baiting; subsequently, the fungus was successfully applied in the industrial propagation and plantation of G. elata in China. Using ex situ seed baiting techniques, Sheng et al. (2012) obtained one mycorrhizal fungus from Cymbidium mannii, an epiphytic orchid species, which proved to be effective for seed germination, and protocorm and seedling development.

D. catenatum Lindley is a perennial, epiphytic orchid from China having medicinal properties. It is used in the treatment of diabetes and improvement of the immune system, as well as an ornamental plant. There has been a drastic reduction in wild populations of $D$. catenatum that has driven the species to the verge of extinction, mainly caused by overexploitation and habitat degradation in recent decades. The low fertility rate and inherently slow growth of the species have also contributed to its current scarcity in the wild. Asymbiotic, sterile, vegetative tissue culture of $D$. catenatum has been successfully developed, but the survival rate of sterile plants and the seedling growth rate are low, meaning this technique is unlikely to contribute to preserving the genetic diversity of this species. In vitro symbiotic seed germination assays of $D$. catenatum using fungal isolates obtained from mature orchid plants have been considered and performed to screen for the presence of effective fungal strains 
(Wu et al., 2012). It was found that the seeds of $D$. catenatum could form a symbiotic relationship with Epulorhiza spp. and Alternaria spp. with low specificity in vitro, but the germination rate was significantly low. Wang et al., (2011) conducted in vitro symbiotic seed germination of $D$. catenatum using fungal strains obtained from protocorms of $D$. chrysanthum via in situ baiting methods, and one fungus (SHH53) successfully improved seed germination and seedling development to stage 5. Other researchers have reported the use of two Tulasnella strains (JC-02 and JC-05) isolated from the roots of $D$. nobile for the symbiotic seed germination of D. catenatum (Wang et al., 2011; Tan et al., 2014). These results demonstrated that the two different strains of Tulasnella varied in their ability to facilitate germination/development of $D$. catenatum seeds in vitro. To the best of our knowledge, no fungal strains isolated from host protocorms have been reported to date. This study addresses the following hypotheses: (1) different fungal strains isolated from the same host protocorm would enhance seed germination; (2) the fungal strains that influence seed germination and seedling development would be from closely related taxa; (3) different fungal strains would influence seed germination at different times after sowing; and (4) the photoperiod would influence seed germination differently under different fungal strains.

\section{Materials and methods}

\section{Plant species}

The study species, D. catenatum, is a lithophyte or epiphyte growing in moderately humid mountains at an elevation of ca. $1600 \mathrm{~m}$. It is widely distributed in central and south China, including Anhui, Fujian, Guangxi, Sichuan, Taiwan, Yunnan, and Zhejiang provinces (Fig. 1). It flowers from March to June with 10\%-17\% fruit set, and seeds become mature during December (Liu et al., 2011).

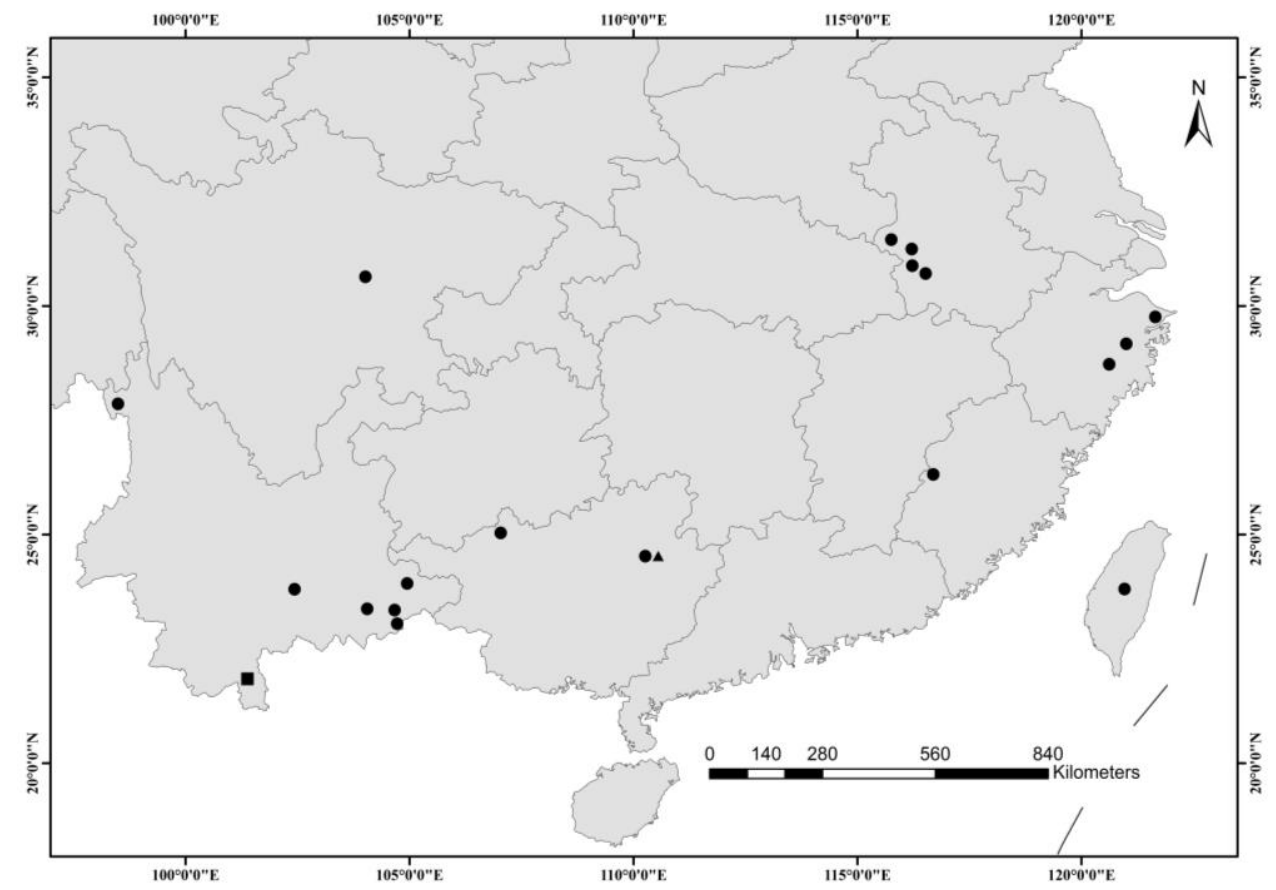

Figure 1. Sketch map of distribution sites of the species D. catenatum by closed circles; sampling sites by closed triangle; and study site by closed squares 


\section{Study sites}

Nearly dehisced fruits set by natural pollination, and substrates for ex situ baiting, were collected from wild populations of D. catenatum in Shuangjiang town, Lipu county, Guangxi Zhuang Autonomous Region, China (Fig. 1). Ex situ baiting to induce protocorm formation and screening for germination-enhancing fungi were performed in Xishuangbanna Tropical Botanical Garden (XTBG; $21^{\circ} 45^{\prime} \mathrm{N}, 101^{\circ} 02^{\prime} \mathrm{E}$; altitude, 580 m), Yunnan Province (Fig. 1).

\section{Seed collection and storage}

The capsules were surface-sterilized using $75 \%$ ethanol, rinsed three times in sterile distilled water, and opened with a sterile scalpel under laminar flow. The seeds were transferred to airtight glass containers with anhydrous calcium chloride. After 4 days, the seeds were stored in a glass vial at $4{ }^{\circ} \mathrm{C}$ for short-term preservation and at $-20{ }^{\circ} \mathrm{C}$ for long-term storage. Seed viability was $89.85 \%$ based on an assessment of approximately 480 seeds using the triphenyl tetrazolium chloride test.

\section{Protocorm induction by ex situ baiting of D. catenatum seeds}

The substrates, consisting of bark, moss, litter, and humus, were collected within $20 \mathrm{~cm}$ of the maternal plants and brought back to the laboratory within $48 \mathrm{~h}$ of harvest. The ex situ baiting mixture was saturated with sterile water, homogenized with a blender, and dispensed into petri dishes $(9.0 \mathrm{~cm}$ in diameter). A designated number of seeds were resuspended in $0.1 \%$ sterilized agar solution and the drops were spread on a nylon mesh (ca. $2 \times 3 \mathrm{~cm}$ ) with $45 \mu$ m pores. Each mesh contained 120 seeds and each petri dish had 4 meshes. All the dishes were incubated in a plant growth chamber (MGC-450HP, Shanghai Yiheng Instruments Co., Ltd, Shanghai, China) at $25 \pm 1{ }^{\circ} \mathrm{C}$ with 12/12 h light/dark (L/D) photoperiod at 1600 lux light intensity. Germination was monitored every 2 weeks, and protocorms that had reached stage 2 and seedlings that had reached stage 3 were then used to extract endophytic fungi.

\section{Isolation of symbiotic fungus from protocorms}

Symbiotic fungus isolation was performed according to the method proposed by $\mathrm{Zi}$ et al. (2014) with slight modifications. Developing protocorms at stage 2 or 3 were gathered and surface-sterilized using sodium hypochlorite solution containing 1\% available chlorine for 3-5 min, and then washed 3-4 times with sterile distilled water. The protocorms were then cut into two parts using a sterilized blade, plated onto petri dishes containing fresh potato dextrose agar (PDA), and then incubated at $25.0 \pm 1.0^{\circ} \mathrm{C}$ in the dark. One complete protocorm was also grown to test the sterilization of the blade. After 3-5 days, once fungal hyphae had emerged from the edge of the broken protocorms, the hyphae tips were sub-cultured from the medium and transferred to new plates with PDA and incubated under the same conditions. The fungal isolates were purified 3-4 times by excising the hyphal tips onto fresh PDA petri dishes.

\section{Molecular identification of fungal isolates and phylogenetic analysis}

Using conventional CTAB method, we extracted DNA from fungi cultured in potato dextrose broth for 5 days. The primers ITS1 and ITS4 (White et al., 1990) were used to amplify nuclear ribosomal internal transcribed spacer (nrITS) using a Biometra gradient 
thermal cycler (070-801, Göttingen). Polymerase chain reaction products were purified using Sangon's purification kit, and sequencing was performed by Sangon Company (Sangon Biotech Co., Ltd, Shanghai, China). The ITS-rDNA sequences obtained from each isolate were compared to those deposited in the GenBank database by BLAST, providing the identification of isolates to the genus or species level when the ITS sequence similarity exceeded $97 \%$ or $99 \%$, respectively (Zi et al., 2014).

Twelve related representative sequences of ITS-rDNA of orchid mycorrhizal fungi from NCBI (https://www.ncbi.nlm.nih.gov/) and eight newly generated sequences were used for phylogenetic analysis. Armillaria sinapina was set as the outgroup, following similar studies (Tan et al., 2014). Alignment of nucleotide sequences was performed by Clustal X version 1.81 (Thompson et al., 1997). Phylogenetic analysis was conducted in MEGA 6.0 (Tamura et al., 2013) with the Maximum Likelihood method based on the best model Kimura 2-parameter + Gamma model $(\mathrm{BIC}=8533.566$, AIC $=8265.917$, $\operatorname{lnL}=-4095.821$ ), with Bootstrap Replications $=1000$, Rates among Sites $=$ uniform rates. Initial tree(s) for the heuristic search was obtained by applying the NearestNeighbor-Interchange method. The tree with the highest log likelihood is shown. The percentage of trees in which the associated taxa clustered together is shown next to the branches.

\section{Testing fungal capacity to promote seed germination}

Seeds of $D$. catenatum were removed from storage at $-20{ }^{\circ} \mathrm{C}$ and kept at ambient temperature overnight. According to the sterilization method of Paphiopedilum spicerianum seeds by Chen et al. (2015), seeds of $D$. catenatum in syringes fitted with $3 \times 3 \mathrm{~cm}$ nylon cloth plot with $45 \mu \mathrm{m}$ pores were first sterilized by washing with sterile distilled water for 5-10 min and then with sodium hypochlorite solution containing $1 \%$ available chlorine, and finally washed with sterile distilled water three to four times. Subsequently, the seeds were transferred to $0.1 \%$ sterile agar solution and ca. 80 seeds were resuspended in $1.0 \mathrm{~mL}$ of agar solution using a pipette and transferred to petri dishes containing $25 \mathrm{~mL}$ of sterile oat meal agar medium (OMA, $4 \mathrm{~g} / \mathrm{L}$ ). Once the seed suspension was completed, each dish was inoculated with one $0.5-\mathrm{cm}^{3}$ piece of fungal inoculum placed in the center of the petri dish, and a sterile PDA plot without fungus was also placed as a control referring to $\mathrm{Zi}$ et al. (2014). Fungus-inoculated petri dishes were randomly assigned to either a continuous dark treatment $(0 / 24 \mathrm{~h}, \mathrm{~L} / \mathrm{D})$ or a $12-\mathrm{h}$ photo period $(12 / 12 \mathrm{~h}, \mathrm{~L} / \mathrm{D})$ with 1800 lux white fluorescent light at $25.0 \pm 1.0^{\circ} \mathrm{C}$. All petri dishes were assessed under a dissecting microscope (Shanghai Bimu Bearing Co Ltd, Shanghai, China), and the exact number of seeds at various stages was recorded for each petri dish after 20,50, and 90 days. Each experiment was replicated four times and petri dishes were placed in the same growth chamber. The percentages of protocorm (stage 2), seedling (stage 3), and seedling development (stage 4) were recorded for each dish, with contaminated dishes being excluded from the assessment.

\section{Statistical analysis of germination and seedling development}

Germination and seedling development were divided into five stages (Table 1) as described by Arditti (1967) with slight modification (both rupture of testa and appearance of protomeristem were regarded as stage 2). Seeds were considered germinated once they reached stage 2 to rule out the possibility that embryo swelling because of imbibed water was counted as germination (Rafter et al., 2016). The number 
of protocorms (P), seedling formation (S), and seedling development (L) were calculated as a percentage of the total number of seeds $(t): P=$ number/t $\times 100$. Generalized linear model was applied on the effect of treatments. Different day intervals and photoperiod conditions were considered as fixed factors. Protocorm formation, seedling formation, and seedling development were considered as dependent variables. All the data were arcsine transformed to obtain normal distributions. Analysis of variance was applied to find differences in seed germination by the effect of treatments and different days separately. Tukey's multiple range test was applied and the significant differences between treatments were analyzed $(P \leq 0.05)$. All the statistical analyses were performed using SPSS version 20.0 software (SPSS Inc., Chicago, USA).

Table 1. Developmental stages and features of symbiotic seed germination of D. catenatum (modified on the basis of Arditti, 1967)

\begin{tabular}{c|c}
\hline Seed germination stage & Description \\
\hline 0 & No germination \\
1 & Imbibed seed, swollen and still covered by testa \\
2 & Protocorm formation and development (rupture of testa, appearance of \\
protomeristem = germination) \\
4
\end{tabular}$\quad \begin{gathered}\text { Seedling formation (emergence of first leaf in early stage) } \\
\text { Seedling development (Emergence of second leaf and continue development) }\end{gathered}$

\section{Results}

\section{Seed baiting to induce protocorms}

After 45 days, 25 out of 88 petri dishes were found with seeds germinated to stage 2 and 3, but no seedlings with two leaves (stage 4) were found. From these 25 dishes, 32 developed protocorms with promeristem and 12 seedlings with one leaf (stage 3 ) were harvested.

\section{Molecular identification of endophytic fungi}

Seven fungal strains (labeled SSCDO-1, SSCDO-3 to SSCDO-8) were successfully isolated from the protocorms and seedlings. All sequences of ITS-rDNA were submitted to GenBank with accession number MH348611-MH348617. Using Blast searches in NCBI, seven of the strains were attributed to the three most common orchid mycorrhizal taxa: the sequences of strains SSCDO-1, SSCDO-3, and SSCDO-4 had 98\% similarity to uncultured Tulasnellaceae clone PM13 (GQ241803.1); SSCDO-5 was similar to the uncultured Tulasnellaceae clone (KX387600.1) with 99\% identity (confirming the allocation of associated fungi in Guangxi by fungal isolation and molecular detection reported by Downing et al. (2017); SSCDO-6 was similar to uncultured Sebacinales (FJ788824.1); SSCDO-7 was close to uncultured Tulasnellaceae clone PM1 (GQ241802.1) and SSCDO-8 matched uncultured Thanatephorus (AB712285.1) (Fig. 2). Phylogenetic analysis of ITS-rDNA demonstrated that the strains SSCDO-1, SSCDO-3, SSCDO-4, SSCDO-5, and SSCDO-7 formed a clade (clade I; BP = 89; Tulasnellaceae); SSCDO-8 and uncultured Thanatephorus AB712285.1 formed a second clade (clade II; BP = 55; Thanatephorus); and SSCDO-6 and uncultured Sebacinales FJ788824.1 a third (clade III; BP =97; Sebacinales) (Fig. 2). Clades II and III are sister clades, paraphyletic to clade I. 


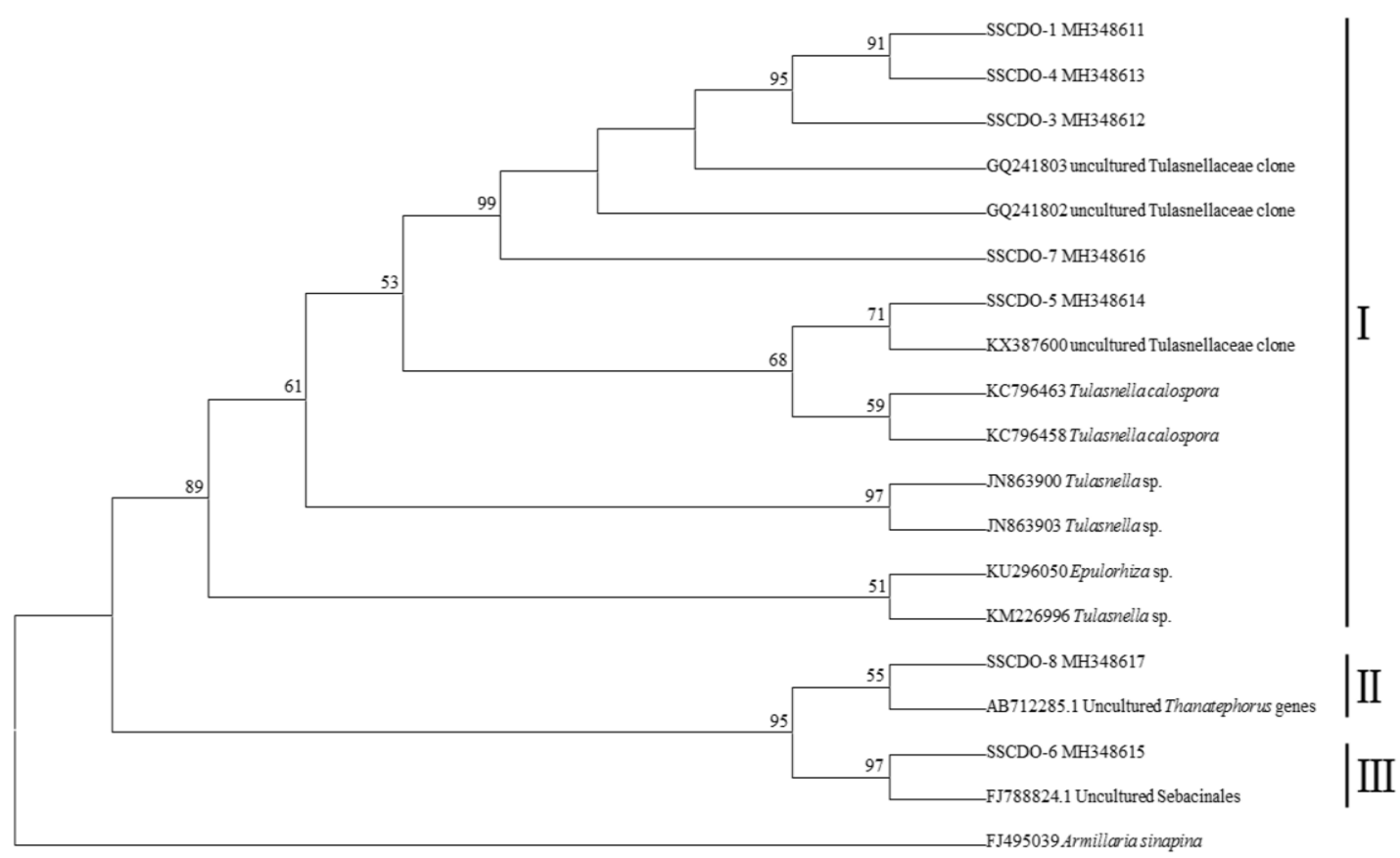

Figure 2. Consensus tree by neighbor-joining of ITS-rDNA sequences of fungi from protocorms of D. catenatum, related sequences, and FJ495039 (Armillaria sinapina) as the outgroup. Bootstrap values $\geq 50 \%$ are shown above the branches. Clades I, II, and II are shown by vertical bars at the right-hand side

\section{Effect of fungal isolates and photoperiod on D. catenatum germination}

Stage 2 - Protocorm formation and development

Different fungal inoculation treatments significantly influenced protocorm formation $\left(F_{8}, 191=27.60 ; p<0.0001\right)$. Protocorm formation was not influenced by time $(20,50$, and 90 days) after seed sowing, but it was significantly influenced by photoperiod $\left(\mathrm{F}_{1,191}=52.59 ; \mathrm{p}<0.0001\right)$. The interactions treatment $\times$ days and photoperiod $\times$ days had no significant influence on protocorm formation $\left(\mathrm{F}_{16}, 191=1.22 ; \mathrm{p}=0.259\right)$; in contrast, the interaction treatment $\times$ photoperiod showed a significant variation on protocorm formation $\left(\mathrm{F}_{8,191}=3.04 ; \mathrm{p}<0.01\right)$. However, the interaction treatment $\times$ days $\times$ photoperiod showed no influence on protocorm formation.

Fungal inoculations SSCDO-5 and SSCDO-8 significantly influenced protocorm formation, followed by SSCDO-6 and SSCDO-7 (Tukey's HSD test). The mean protocorm formation after sowing was $44.56 \pm 3.08 \%$ at 20 days, $42.33 \pm 2.85 \%$ at 50 days, and $44.56 \pm 2.42 \%$ at 90 days, with no significant differences between different days $\left(F_{2,191}=0.215 ; p=0.807\right)$. After 20 days, different treatments showed significant differences in protocorm formation $\left(\mathrm{F}_{8,57}=8.052 ; \mathrm{p}<0.0001\right)$, with SSCDO-5 having the most influence followed by SSCDO-1, SSCDO-8, and SSCDO-2. In addition, treatments showed significant differences on protocorm formation after 50 days $\left(\mathrm{F}_{8}\right.$, $62=5.44 ; P<0.0001)$ and after 90 days $\left(\mathrm{F}_{8}, 70=9.699 ; \mathrm{p}<0.0001\right)$. In particular, treatments SSCDO-8 and SSCDO-5 highly influenced the protocorm formation after 50 and 90 days. Protocorm formation was always improved with 12/12 L/D conditions versus $0 / 24 \mathrm{~L} / \mathrm{D}$ conditions (Fig. 3a), significantly for most treatments, but not for SSCDO-5 and SSCDO-8 (Table 3). 

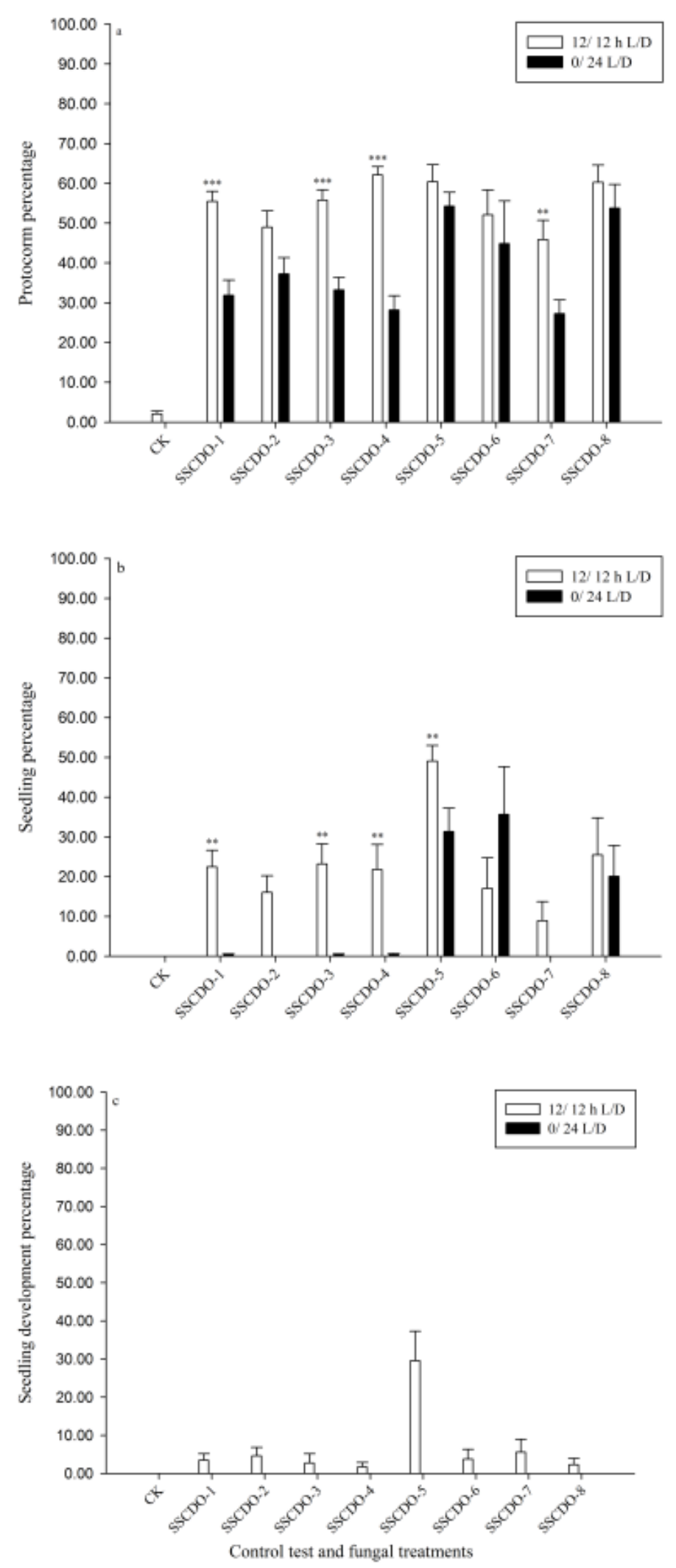

Figure 3. The effects of fungal treatments on each seed germination stage after 90 days of inoculation. a Protocorm formation (\%); $\boldsymbol{b}$ Seedling formation (\%); $\boldsymbol{c}$ Seedling development (\%). Asterisks denote statistically significant differences between light/dark treatments with the same fungus $(* * P<0.01 ; * * * P<0.0001)$ 


\section{Stage 3 - Seedling formation}

Fungal inoculation treatments significantly influenced seedling formation $\left(\mathrm{F}_{8,191}=13.19 ; \mathrm{p}<0.0001\right)$, as did days and photoperiod $\left(\mathrm{F}_{1,191}=16.82 ; \mathrm{p}<0.0001\right.$ and $\mathrm{F}_{1,191}=17.86 ; \mathrm{p}<0.0001$, respectively). The interaction treatment $\times$ days did not influence the growth of seedling formation $\left(\mathrm{F}_{16,191}=1.59 ; \mathrm{p}=0.08\right)$, whereas the interaction treatment $\times$ photoperiod significantly influenced seedling formation $\left(\mathrm{F}_{8,191}=3.46 ; \mathrm{p}<0.001\right)$, as did the interaction days $\times$ photoperiod. However, the interaction treatment $\times$ days $\times$ photoperiod had no influence on seedling formation $\left(\mathrm{F}_{16,191}=1.32 ; \mathrm{p}=0.192\right)$.

Treatment with SSCDO-5 significantly increased seedling formation compared with control and other treatments, followed by SSCDO-6 and SSCDO-8 (Tukey's HSD multiple range test; Table 2).

Table 2. Generalized linear model shows that the effect of treatments (eight fungal strains and control test), different days after seed sowing (20,50 and 90 days) and photoperiod $(0 / 24 h L / D, 12 / 12 h$ L/D) on protocorm formation, seedlings formation and seedlings development of $D$. catenatum

\begin{tabular}{|c|c|c|c|c|}
\hline Source & Dependent variable & Df & Mean square & F-test \\
\hline \multirow{3}{*}{ Treatment } & ProtocormF & 8,191 & 5279.7 & $27.60 * * *$ \\
\hline & SeedlingF & 8,191 & 2939.5 & $13.19 * * *$ \\
\hline & SeedlingD & 8,191 & 337.8 & $10.59 * * *$ \\
\hline \multirow{3}{*}{ Days } & ProtocormF & 2,191 & 240.1 & $1.26^{\mathrm{ns}}$ \\
\hline & SeedlingF & 2,191 & 3747.5 & $16.82 * * *$ \\
\hline & SeedlingD & 2,191 & 731.8 & $22.95^{* * *}$ \\
\hline \multirow{3}{*}{ Photoperiod } & ProtocormF & 1,191 & 10060.8 & $52.59 * * *$ \\
\hline & SeedlingF & 1,191 & 3980.1 & $17.86^{* * *}$ \\
\hline & SeedlingD & 1,191 & 1245.0 & $39.04 * * *$ \\
\hline \multirow{3}{*}{ Treatment $\times$ days } & ProtocormF & 16,191 & 233.7 & $1.22^{\mathrm{ns}}$ \\
\hline & SeedlingF & 16,191 & 353.3 & $1.59^{\mathrm{ns}}$ \\
\hline & SeedlingD & 16,191 & 115.9 & $3.63 * * *$ \\
\hline \multirow{3}{*}{ Treatment $\times$ light } & ProtocormF & 8,191 & 582.4 & $3.04 * *$ \\
\hline & SeedlingF & 8,191 & 772.0 & $3.46^{* *}$ \\
\hline & SeedlingD & 8,191 & 337.8 & $10.59 * * *$ \\
\hline \multirow{3}{*}{ Days $\times$ light } & ProtocormF & 2,191 & 127.4 & $0.67^{\mathrm{ns}}$ \\
\hline & SeedlingF & 2,191 & 1946.4 & $8.73 * * *$ \\
\hline & SeedlingD & 2,191 & 731.8 & $22.95 * * *$ \\
\hline \multirow{3}{*}{ Fungi $\times$ days $\times$ light } & ProtocormF & 16,191 & 167.4 & $0.88^{\mathrm{ns}}$ \\
\hline & SeedlingF & 16,191 & 294.7 & $1.32^{\mathrm{ns}}$ \\
\hline & SeedlingD & 16,191 & 115.9 & $3.63 * * *$ \\
\hline \multirow{3}{*}{ Error } & ProtocormF & 138,191 & 191.3 & \\
\hline & SeedlingF & 138,191 & 222.8 & \\
\hline & SeedlingD & 138,191 & 31.9 & \\
\hline
\end{tabular}

Suffix $\mathrm{F}=$ formation; suffix $\mathrm{D}=$ development; ***indicates significance level $\mathrm{P}<0.0001$; **indicates significance level $\mathrm{P}<0.001$; ns $=$ not significant. DF values showing number of variables in correspondence to the total number of replicates of the each factor 
Mean seedling formation was $5.01 \pm 1.74 \%$ at 20 days, $17.36 \pm 2.77 \%$ at 50 days, and $23.92 \pm 2.85 \%$ at 90 days after sowing with no significant differences on the production of seedlings in response to different days. In addition, different fungal strains showed significant differences on seedling formation at 20 days $\left(\mathrm{F}_{8,57}=43.15 ; \mathrm{p}<0.0001\right)$, at 50 days $\left(\mathrm{F}_{8,62}=4.18 ; \mathrm{p}<0.001\right)$, and at 90 days after seed sowing $\left(\mathrm{F}_{8,70}=2.098 ; \mathrm{p}<0.0001\right)$. In general, light (12/12 L/D conditions) significantly influenced seedling growth compared with darkness (e.g., for SSCDO-1, SSCDO-3, SSCDO-4, and SSCDO-5), whereas seedling growth was not significantly different for SSCDO-8 (Table 2; Fig. 3b).

\section{Stage 4 - Seedling development}

The fungal strains significantly influenced seedling development $\left(\mathrm{F}_{8}, 191=10.59\right.$; $\mathrm{p}<0.0001$ ), and this varied significantly at different times after seed sowing $\left(F_{2,191}=22.95 ; \mathrm{p}<0.0001\right)$. In addition, the photoperiod significantly influenced seedling development $\left(\mathrm{F}_{1,191}=39.04 ; \mathrm{p}<0.0001\right)$. Interestingly, the interaction fungal inoculation treatment $\times$ days also showed a significant variation on seedling development $\left(\mathrm{F}_{16}\right.$, $191=3.63 ; \mathrm{p}<0.0001)$, as did the dual interaction treatment $\times$ photoperiod $\left(\mathrm{F}_{8,1}=10.59\right.$; $\mathrm{p}<0.0001)$. Moreover, the dual interaction days $\times$ photoperiod showed significant differences on seedling development and the interaction treatment $\times$ days $\times$ photoperiod also showed significant differences $\left(\mathrm{F}_{16,191}=3.63 ; \mathrm{p}<0.0001\right)$.

In particular, the fungal strain SSCDO-5 significantly influenced seedling development compared with control and other treatments (Tukey's HSD test; Table 3). There was no seedling development 20 days after seed sowing, although seedling development was found at 50 days $(1.57 \pm 0.86 \%)$ and 90 days $(7.76 \pm 1.77 \%)$, with significant differences in seedling development at different days after sowing by the effect of all treatments $\left(\mathrm{F}_{2,191}=11.45 ; \mathrm{p}<0.0001\right)$. In addition, different fungal strains exhibited significant differences in seedling development at 50 days $\left(\mathrm{F}_{8,62}=4.98 ; \mathrm{p}<0.0001\right)$ and at 90 days $\left(\mathrm{F}_{8,70}=3.804 ; \mathrm{p}<0.001\right)$ (Table 2). Among these, SSCDO-5 significantly increased the seedling development at 50 and 90 days (Table 3). Seedling development only occurred under light conditions (12/12 L/D) with the different treatments (Fig. 3c); there was no seedling development in darkness.

\section{Discussion}

\section{Ex situ baiting isolation}

The present study in D. catenatum showed that the ex situ baiting technique resulted in the successful isolation of specific symbiotic mycorrhizal fungal strains that effectively induced seed protocorm formation. In our study, after 1.5 months, protocorms and seedlings with one leaf were successfully induced in $0.42 \%$ of seeds by ex situ baiting, and compatible and adaptive fungal strains were obtained successfully from host protocorms. This method could be considered for broader application to induce protocorm formation and to isolate mycorrhizal symbionts in other epiphytic orchids.

\section{Phylogeny of symbiotic fungi}

The fungi isolated from the protocorms in the present study belong to the families Tulasnellaceae, Ceratobasidiaceae, and Sebacinales. All the fungal isolates belonging to the clades of Tulasnellaceae, Sebacinales, and Thanatephorus had high similarity to fungi from the roots of D. catenatum (Xing et al., 2013). Taxa in Tulasnellaceae have often 
been found in association with tropical epiphytic and terrestrial orchids (Sathiyadash et al., 2014; Zi et al., 2014; Zhou and Gao, 2016). This study is the first report on symbiotic seed germination in the species $D$. catenatum induced by fungi from the host protocorm origin induced using ex situ baiting techniques but not from roots.

Table 3. The effect of different days and treatments on differences in mean percentage growth of protocorms formation, seedlings formation and seedlings development on D. catenatum

\begin{tabular}{|c|c|c|c|c|}
\hline \multirow{2}{*}{$\begin{array}{l}\text { Seeds after } \\
\text { sowing }\end{array}$} & \multirow[t]{2}{*}{ Treatment } & $\begin{array}{l}\text { Protocorm } \\
\text { formation }\end{array}$ & $\begin{array}{c}\text { Seedling } \\
\text { formation }\end{array}$ & $\begin{array}{c}\text { Seedling } \\
\text { development }\end{array}$ \\
\hline & & Mean & Mean & Mean \\
\hline \multirow{10}{*}{20 days } & SSCDO-1 & $56.3 \pm 5.3 b c$ & $0.9 \pm 0.5 \mathrm{a}$ & 0 \\
\hline & SSCDO-2 & $51.1 \pm 5.1 b c$ & $0.0 \pm 0.0 \mathrm{a}$ & 0 \\
\hline & SSCDO-3 & $49.3 \pm 6.6 b c$ & $2.0 \pm 1.1 \mathrm{a}$ & 0 \\
\hline & SSCDO-4 & $45.7 \pm 9.5 b c$ & $0.5 \pm 0.5 \mathrm{a}$ & 0 \\
\hline & SSCDO-5 & $65.6 \pm 5.2 \mathrm{c}$ & $41.0 \pm 5.7 b$ & 0 \\
\hline & SSCDO-6 & $45.9 \pm 11.0 \mathrm{bc}$ & $3.1 \pm 3.1 \mathrm{a}$ & 0 \\
\hline & SSCDO-7 & $29.6 \pm 7.5 \mathrm{ab}$ & $0.0 \pm 0.0 \mathrm{a}$ & 0 \\
\hline & SSCDO-8 & $53.8 \pm 5.2 b c$ & $0.9 \pm 0.6 \mathrm{a}$ & 0 \\
\hline & CK & $0.7 \pm 0.5 \mathrm{a}$ & $0.0 \pm 0.0 \mathrm{a}$ & 0 \\
\hline & $\operatorname{ANOVA}(\mathrm{F}), \mathrm{N}=8, \mathrm{DF}=57$ & $8.05 * * *$ & $43.15^{* * *}$ & - \\
\hline \multirow{10}{*}{50 days } & SSCDO-1 & $45.0 \pm 5.6 b$ & $17.6 \pm 4.8 \mathrm{abc}$ & $0.0 \pm 0.0 \mathrm{a}$ \\
\hline & SSCDO-2 & $44.5 \pm 5.1 b$ & $9.7 \pm 3.8 \mathrm{abc}$ & $0.0 \pm 0.0 \mathrm{a}$ \\
\hline & SSCDO-3 & $45.5 \pm 5.8 b$ & $16.7 \pm 7.0 \mathrm{abc}$ & $0.0 \pm 0.0 \mathrm{a}$ \\
\hline & SSCDO-4 & $47.5 \pm 9.1 b$ & $9.3 \pm 6.7 \mathrm{ab}$ & $0.0 \pm 0.0 \mathrm{a}$ \\
\hline & SSCDO-5 & $50.3 \pm 3.3 b$ & $41.7 \pm 2.4 c$ & $14.1 \pm 6.3 b$ \\
\hline & SSCDO-6 & $53.3 \pm 12.2 b$ & $36.2 \pm 14.6 b c$ & $0.0 \pm 0.0 \mathrm{a}$ \\
\hline & SSCDO-7 & $33.6 \pm 6.8 b$ & $0.0 \pm 0.0 \mathrm{a}$ & $0.0 \pm 0.0 \mathrm{a}$ \\
\hline & SSCDO-8 & $56.4 \pm 8.7 b$ & $25.0 \pm 12.0 \mathrm{abc}$ & $0.0 \pm 0.0 \mathrm{a}$ \\
\hline & CK & $0.0 \pm 0.0 \mathrm{a}$ & $0.0 \pm 0.0 \mathrm{a}$ & $0.0 \pm 0.0 \mathrm{a}$ \\
\hline & $\operatorname{ANOVA}(\mathrm{F}), \mathrm{N}=8, \mathrm{DF}=62$ & $5.44 * * *$ & $4.18^{* *}$ & $4.98 * * *$ \\
\hline \multirow{10}{*}{90 days } & SSCDO-1 & $43.0 \pm 4.3 b$ & $24.2 \pm 6.8$ & $6.4 \pm 2.6 a$ \\
\hline & SSCDO-2 & $39.6 \pm 5.9 b$ & $18.1 \pm 6.5 \mathrm{ab}$ & $7.7 \pm 3.4 \mathrm{a}$ \\
\hline & SSCDO-3 & $43.5 \pm 4.7 b$ & $21.5 \pm 7.8 \mathrm{ab}$ & $4.8 \pm 4.1 \mathrm{a}$ \\
\hline & SSCDO-4 & $51.5 \pm 5.2 b$ & $25.7 \pm 8.2 \mathrm{ab}$ & $2.6 \pm 1.7 \mathrm{a}$ \\
\hline & SSCDO-5 & $58.2 \pm 5.0 \mathrm{~b}$ & $40.5 \pm 10.3 b$ & $32.4 \pm 11.7 b$ \\
\hline & SSCDO-6 & $47.8 \pm 8.4 b$ & $30.1 \pm 10.6 \mathrm{ab}$ & $5.2 \pm 3.5 \mathrm{a}$ \\
\hline & SSCDO-7 & $47.7 \pm 2.6 b$ & $13.4 \pm 6.8 \mathrm{ab}$ & $8.3 \pm 4.9 \mathrm{a}$ \\
\hline & SSCDO-8 & $61.2 \pm 4.3 b$ & $38.3 \pm 9.4 b$ & $3.5 \pm 2.4 \mathrm{a}$ \\
\hline & CK & $0.0 \pm 0.0 \mathrm{a}$ & $0.0 \pm 0.0 \mathrm{a}$ & $0.0 \pm 0.0 \mathrm{a}$ \\
\hline & $\operatorname{ANOVA}(\mathrm{F}), \mathrm{N}=8, \mathrm{DF}=70$ & $9.699 * * *$ & $2.098 * * *$ & $3.804 * *$ \\
\hline
\end{tabular}

$\mathrm{CK}=$ Control. Values are provided as mean \pm S.E. In a column, values followed by a different lowercase letter(s) are significantly different at the 5\% level according to Tukey's HSD multiple range test. ***Significance level $P<0.0001$. **Significance level $P<0.001$ 


\section{In vitro symbiotic seed germination}

\section{Fungal treatment}

It has been suggested that in theory any fungal strain isolated from the protocorms of one species may promote seed germination and protocorm formation in that species, and this has been proved experimentally on $D$. catenatum in the present study. The strains SSCDO-1, SSCDO-2, SSCDO-3, SSCDO-4, and SSCDO-7 showed similar effects on protocorm formation and development (Table 4; Fig. 4b) represented by the fungus SSCDO-4. The percentage of seedlings with one leaf was higher with SSCDO-1, SSCDO-3, and SSCDO-4 than with SSCDO-2 and SSCDO-7, but no significant differences were found with the other fungal strains. Steinfort et al. (2010) found a similar tendency in the germination of Bipinnula fimbriata at stage 2, with the fungal strain P2VT-03 showing a significantly higher germination rate than the strains F2VT02 and F2VT-03, although all of them belonged to the same species, Tulasnella calospora; the strain F6VT-02 showed a stronger effect on seed germination at stage 2 than strain F3VC-02 of the same species. Xu et al. (2017) found that a strain of $T$. calospora, Tco2, showed more effective promotion of seed germination and protocorm differentiation in Epidendrum secundum than another strain of the same species. Results from the present study also suggested that fungal strains of the same species (Tulasnellaceae) vary in their influence on germination and growth of seeds.

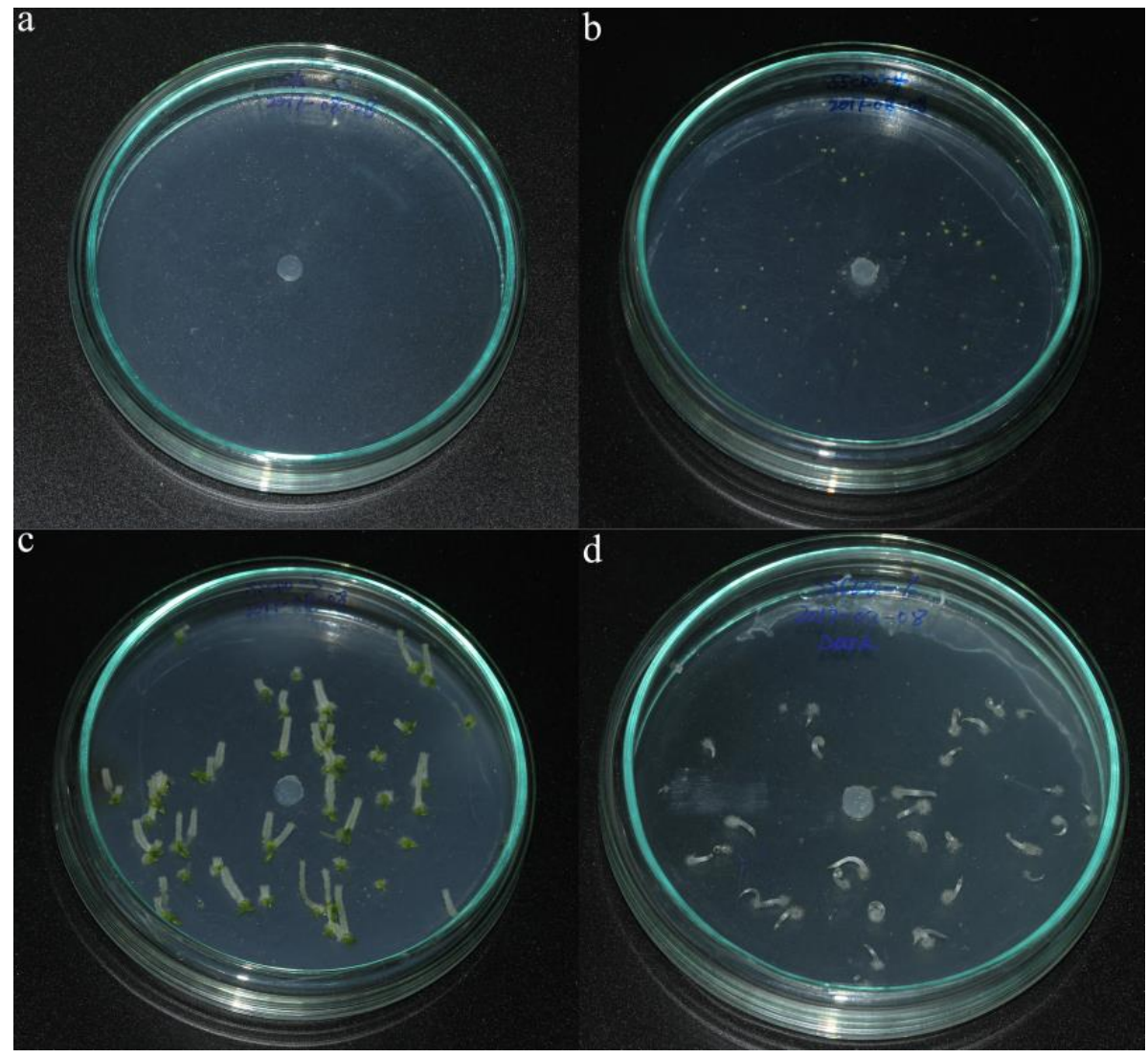

Figure 4. Symbiotic seed germination of D. catenatum 90 days after sowing. $\boldsymbol{a}$ Control test. $\boldsymbol{b}$ Protocorm formation and seedling formation following inoculation with varying fungal treatments (represented by SSCDO-4) under light conditions. $c$ Seedling development (with

SSCDO-5 inoculation) in light conditions. $\boldsymbol{d}$ Abnormal seedlings in dark conditions (represented by SSCDO-6) 
After 90 days with the control treatment, protocorms had still not formed (Fig. 4a); however, after only 20 days of treatment with the fungal strains, protocorms had formed, indicating that fungal inoculation plays a significant role in germination. The fungal strains SSCDO-5, SSCDO-6, and SSCDO-8 significantly influenced the growth of protocorms and seedling formation (one-leaf seedlings) measured at different times after sowing. In particular, SSCDO-5 significantly influenced protocorm formation and seedling development in D. catenatum (more so than other fungal strains), promoting the best seedling development and maximum number of seedlings with two leaves and long roots (Table 4; Fig. 4c). Potentially, then, SSCDO-5 might be of use in efficiently initiating seed germination and promoting further seedling development, and this could be potential for mass seedling propagation in a conservation program.

Table 4. Effect of fungal inoculation treatment on protocorm formation (\%), seedling formation (\%), and seedling development (\%) on the species $D$. catenatum under in vitro conditions

\begin{tabular}{c|c|c|c}
\hline \multirow{2}{*}{ Treatments } & Protocorm formation (\%) & Seedling formation (\%) & Seedling Development (\%) \\
\cline { 2 - 4 } & Mean \pm S.E & Mean \pm S.E & Mean \pm S.E \\
\hline SSCDO-1 & $47.6 \pm 3.0 \mathrm{bc}$ & $15.1 \pm 3.4 \mathrm{abc}$ & $2.4 \pm 1.1 \mathrm{a}$ \\
SSCDO-2 & $44.6 \pm 3.2 \mathrm{bc}$ & $10.0 \pm 3.1 \mathrm{abc}$ & $2.9 \pm 1.4 \mathrm{a}$ \\
SSCDO-3 & $46.1 \pm 3.2 \mathrm{bc}$ & $13.4 \pm 3.8 \mathrm{abc}$ & $1.6 \pm 1.4 \mathrm{a}$ \\
SSCDO-4 & $48.6 \pm 4.2 \mathrm{bc}$ & $13.2 \pm 4.4 \mathrm{abc}$ & $1.0 \pm 0.7 \mathrm{a}$ \\
SSCDO-5 & $57.7 \pm 2.8 \mathrm{c}$ & $41.1 \pm 3.9 \mathrm{~d}$ & $16.3 \pm 5.3 \mathrm{~b}$ \\
SSCDO-6 & $49.1 \pm 5.7 \mathrm{bc}$ & $24.9 \pm 6.9 \mathrm{~cd}$ & $2.2 \pm 1.5 \mathrm{a}$ \\
SSCDO-7 & $37.4 \pm 3.6 \mathrm{~b}$ & $4.9 \pm 2.7 \mathrm{ab}$ & $3.0 \pm 1.9 \mathrm{a}$ \\
SSCDO-8 & $57.5 \pm 3.5 \mathrm{c}$ & $23.2 \pm 6.1 \mathrm{bcd}$ & $1.3 \pm 1.0 \mathrm{a}$ \\
CK & $0.2 \pm 0.2 \mathrm{a}$ & $0.0 \pm 0.0 \mathrm{a}$ & $0.0 \pm 0.0 \mathrm{a}$ \\
\hline ANOVA (F), & $21.0 * * *$ & $7.96 * * *$ & $5.26 * * *$ \\
N = 8, & & \\
DF $=191$ & & & \\
\hline
\end{tabular}

$\mathrm{CK}=$ control. Values are given as mean \pm S.E. In a column, values followed by a different lowercase letter(s) are significantly different at the 5\% level according to Tukey's HSD multiple range test. $* * *$ Significance level $P<0.0001$. The row in SSCDO-5 boldface indicates the significantly higher value on different growth formation as compared to other treatments)

The present results also support the hypothesis that mycorrhizal fungi isolated from protocorms would produce seed germination and advance development to a higher stage, with high compatibility and adaptivity (Sharma et al., 2003). Several previous studies have put forward a similar hypothesis for various terrestrial and epiphytic orchids (Sharma et al., 2003; Sathiyadash et al., 2014; Zi et al., 2014; Wang et al., 2016; Shao et al., 2017).

Days

The different observation days after sowing time play a significant role for the percentage of seed germination, with protocorm formation being higher at 20 and 90 days. Subsequently, the percentage of seedling formation was higher at 50 and 90 days, and while there was no seedling development (two-leaf seedlings) at 20 days, two-leaf seedlings were found at 50 and 90 days after sowing following fungal inoculation 
treatment. In addition, protocorm formation had increased at 20 days (mean $=49.63 \%$ ), at 90 days $($ mean $=48.07 \%)$, and at 50 days $($ mean $=46.79 \%)$ with all treatments. Seedling formation increased only gradually over time, and developed seedlings (twoleaf stage) were only found at 90 days (none at 20 or 50 days), in line with a previous study (Huang et al., 2018). Another study in D. catenatum reported seedling development (stage 5) after 12 weeks (84 days) under optimal conditions under the influence of fungal strains (Wang et al., 2011), similar to the findings of the present study, and Tan et al. (2014) also reported that seed germination was higher at stage 3 and lower at stages 4 and 5 under the influence of an effective fungal strain JC-05. Overall, in the present study, while periods of 20 and 50 days after sowing were significant for the formation of protocorm and seedlings during the earlier stages of seed germination, seedling development significantly increased by 90 days under the influence of fungal inoculation treatments.

\section{Photoperiod}

In the present study, the response of photoperiod is positive for seed germination and seedling development. There was a significant variability in germination rate under the light photoperiod (12/12 h L/D) with all fungal strains when considering seedlings with two leaves, indicating different degrees of compatibility between seeds and fungal strains. No seedlings were formed in the dark conditions, indicating that light is likely a key ecological factor for protocorm development and seedling formation. Interestingly, a small number of seedlings with one leaf were found under dark conditions, but the seedling development that did occur was not via leaves but via roots (Fig. 4d), reflecting results reported in previous studies (Tan et al., 2014; Cui et al., 2012).

\section{Conclusion}

Dendrobium catenatum, an epiphytic orchid, is now rare and endangered in China, its population having been reduced by over exploitation for traditional medicine. Consequently, it has become necessary to develop a standard protocol for efficient plant reproduction in situ. This study confirms that symbiotic mycorrhizal fungi (the strains SSCDO-5) support protocorm formation, seedling formation, and sapling development under light conditions as observed at 20-90 days after sowing. Fungal strains of the same species (Tulasnellaceae spp.) isolated from protocorms might be more compatible and specific. Performance of strain SSCDO-5 should be tested in the wild when considering direct sowing for reintroduction and conservation. Ex situ baiting techniques for symbiotic seed germination might prove valuable for the conservation of D. catenatum, helping in future orchid production, reintroduction in both in situ and ex situ conservation efforts, and under in vitro experimental conditions. We believe that direct sowing of $D$. catenatum seeds inoculated with specific symbiotic fungi might prove successful for reintroduction or orchid plant production, and would encourage sustainable management for traditional medicinal practices.

Acknowledgements. The authors thank Ms. Xiu-Qing Xie for her kind assistance in preparatory laboratory work and symbiotic seed germination in vitro and Dr. Zhi-Yong Liao for his advice on data analysis. 


\section{REFERENCES}

[1] Arditti, J. (1967): Factors affecting the germination of orchid seeds. - The Botanical Review 33: 1-97.

[2] Brundrett, M. C., Scade, A., Batty, A. L., Dixon, K. W., Sivasithamparam, K., (2003): Development of in situ and ex situ seed baiting techniques to detect mycorrhizal fungi from terrestrial orchid habitats. - Mycological Research 107: 1210-1220.

[3] Chen, Y., Goodale, U. M., Fan, X. L., Gao, J. Y. (2015): Asymbiotic seed germination and in vitro seedling development of Paphiopedilum spicerianum: an orchid with an extremely small population in China. - Global Ecology and Conservation 3: 367-378.

[4] Chutima, R., Dell, B., Lumyong, S. (2011): Effects of mycorrhizal fungi on symbiotic seed germination of Pecteilis susannae (L.) Rafin (Orchidaceae), a terrestrial orchid in Thailand. - Symbiosis 53: 149-156.

[5] Cruz-Higareda, J. B., Luna-Rosales, B. S., Barba-Alvarez, A. (2015): A novel seed baiting technique for the epiphytic orchid Rhynchostele cervantesii, a means to acquire mycorrhizal fungi from protocorms. - Lankesterlana 15: 67-76.

[6] Cui, Q. H., Sun, Y. Y., Li, K., Duan, M. L. (2012): Seed preservation and germination process of morphological development of Dendrobium devonianum Paxt. - Acta Agriculturae Universitatis Jiangxiensis 34: 0533-0536 (in Chinese with English Abstract).

[7] Downing, J. L., Liu, H., Shao, S. C., Wang, X. L., McCormick, M., Deng, R. Y., Gao, J. Y. (2017): Contrasting changes in biotic interactions of orchid populations subject to conservation introduction vs. conventional translocation in tropical China. - Biological Conservation 212: 29-38.

[8] Fracchia, S., Aranda-Rickert, A., Rothen, C., Sede, S. (2016): Associated fungi, symbiotic germination and in vitro seedling development of the rare Andean terrestrial orchid Chloraea riojana. - Flora 224: 106-111.

[9] Herrera, H., Valadares, R., Contreras, D., Bashan, Y., Arriagada, C. (2016): Mycorrhizal compatibility and symbiotic seed germination of orchids from the coastal range and Andes in south central Chile. - Mycorrhiza 27: 175-188.

[10] Huang, H., Zi, X. M., Lin, H., Gao, J. Y. (2018): Host-specificity of symbiotic mycorrhizal fungi for enhancing seed germination, protocorm formation and seedling development of over-collected medicinal orchid, Dendrobium devonianum. - Journal of Microbiology 56: 42-48.

[11] Johnson, T. R., Stewart, S. L., Dutra, D., Kane, M. E., Richardson, L. (2007): Asymbiotic and symbiotic seed germination of Eulophia alta (Orchidaceae) - preliminary evidence for the symbiotic culture advantage. - Plant Cell Tissue Organ 90: 313-323.

[12] Khamchatra, N., Dixon, K. W., Tantiwiwat, S., Piapukiew, J. (2016): Symbiotic seed germination of an endangered epiphytic slipper orchid, Paphiopedilum villosum (Lindl.) Stein. from Thailand. - South African Journal of Botany 104: 76-81.

[13] Liu, Z. J., Zhang, Y. T., Wang, Y., Huang, Q. H., Chen, S. C., Chen, L. J. (2011): Recent developments in the study of rapid propagation of Dendrobium catenatum Lindl. with a discussion on its scientific and Chinese names. - Plant Science Journal 29: 763-772 (in Chinese with English Abstract).

[14] Masuhara, G., Katsuya, K. (1994): In situ and in vitro specificity between Rhizoctonia spp. and Spiranthes sinensis (Persoon) Ames. var. amoena (M. bieberstein) Hara (Orchidaceae). - New Phytologist 127: 711-718.

[15] Park, E. J., Lee, W. Y. (2013): In vitro symbiotic germination of myco-heterotrophic Gastrodia elata by Mycena species. - Plant Biotechnology Reports 7: 185-191.

[16] Rafter, M., Yokoya, K., Schofield, E. J., Zettler, L. W., Sarasan, V. (2016): Non-specific symbiotic germination of Cynorkis purpurea (Thouars) Kraezl., a habitat-specific terrestrial orchid from the central highlands of Madagascar. - Mycorrhiza 26: 541-552. 
[17] Rasmussen, H. N., Whigham, D. F. (1993): Seed ecology of dust seeds in situ: A new study technique and its application in terrestrial orchids. - American Journal of Botany 80: 1374-1378.

[18] Rasmussen, H. N., Dixon, K. W., Jersakova, J., Tesitelova, T. (2015): Germination and seedling establishment in orchids: a complex of requirements. - Annals of Botany 116: 391-402.

[19] Sathiyadash, K., Muthukumar, T., Murugan, S. B., Sathishkumar, R., Pandey, R. R. (2014): In vitro symbiotic seed germination of South Indian endemic orchid Coelogyne nervosa. - Mycoscience 55: 183-189.

[20] Selosse, M-A., Roy, M. (2009): Green plants that feed on fungi: facts and questions about mixotrophy. - Trends in Plant Science 14: 64-70.

[21] Shao, S. C., Burgess, K. S., Cruse-Sanders, J. M., Liu, Q., Fan, X. L., Huang, H., Gao, J. Y. (2017): Using in situ symbiotic seed germination to restore over-collected medicinal orchids in southwest China. - Frontiers in Plant Science 8: 888.

[22] Sharma, J., Zettler, L. W., Van Sambeek, J. W., Ellerieck, M. R., Starbuck, C. J., (2003): Symbiotic seed germination and mycorrhizae of the federally threatened Platanthera praeclara (Orchidaceae). - The American Midland Naturalist 149: 104-120.

[23] Sheng, C. L., Li, Y. I., Gao, J. Y. (2012): Ex situ symbiotic seed germination, isolation and identification of effective symbiotic fungus in Cymbidium mannii (Orchidaceae). Chinese Journal of Plant Ecology 36: 859-869 (in Chinese with English Abstract).

[24] Steinfort, U., Verdugo, G., Besoain, X., Cisternas, M. A. (2010): Mycorrhizal association and symbiotic germination of the terrestrial orchid Bipinnula fimbriata (Poepp.) Johnst (Orchidaceae). - Flora 205: 811-817.

[25] Stewart, S. L., Kane, M. E., (2007): Symbiotic seed germination and evidence for in vitro mycobiont specificity in Spiranthes brevilabris (Orchidaceae) and its implications for species-level conservation. - In Vitro Cellular \& Developmental Biology - Plant 43: 178186.

[26] Swangmaneecharern, P., Serivichyaswat, P., Nontachaiyapoom, S. (2012): Promoting effect of orchid mycorrhizal fungi Epulorhiza isolates on seed germination of Dendrobium orchids. - Scientia Horticulturae 148: 55-58.

[27] Tamura, K., Stecher, G., Peterson, D., Filipski, A., Kumar, S. (2013): MEGA6: molecular evolutionary genetics analysis version 6.0. - Molecular Biology and Evolution 30: 27252729.

[28] Tan, X. M., Wang, C. L., Chen, X. M., Zhou, Y. Q., Wang, Y. Q., Luo, A. X., Liu, Z. H., Guo, S. X. (2014): In vitro seed germination and seedling growth of an endangered epiphytic orchid, Dendrobium officinale, endemic to China using mycorrhizal fungi (Tulasnella sp.). - Scientia Horticulturae 165: 62-68.

[29] Thompson, J. D., Gibson, T. J., Plewniak, F., Jeanmougin, F., Higgins, D. G., (1997): The CLUSTAL_X windows interface: flexible strategies for multiple sequence alignment aided by quality analysis tools. - Nuclear Acid Research 25: 4876-4882.

[30] Wang, H., Fang, H. Y., Wang, Y. Q., Duan, L. S., Guo, S. X. (2011): In situ seed baiting techniques in Dendrobium officinale Kimuraet migo and Dendrobium nobile Lindl.: The endangered Chinese endemic Dendrobium (Orchidaceae). - World Journal of Microbial Biotechnology 27: 2051-2059.

[31] White, T. J. B., Bruns, T., Lee, S., Taylor, J. (1990): Amplification and Direct Sequencing of Fungal Ribosomal RNA Genes for Phylogenetics. - In: Inis M. A., Gelfand, D. H., Sninsky, J. J., White, T. J. (ed.) PCR Protocols: A Guide to Methods and Applications. Academic Press, San Diego.

[32] Wu, H. F., Song, X. Q., Liu, H. X. (2012): Ex-situ symbiotic seed germination of Dendrobium catenatum. - Acta Ecologica Sinica 32: 2491-2497 (in Chinese with English Abstract). 
[33] Xing, X. K., Ma, X. T., Deng, Z. H., Chen, J., Wu, F. Z., Guo, S. X. (2013): Specificity and preference of mycorrhizal associations in two species of the genus Dendrobium (Orchidaceae). - Mycorrhiza 23: 317-324.

[34] Xu, J. T., Guo, S. X. (1989): Fungus associated with nutrition of seed germination of Gastrodia elata: Mycena osmundicola Lange. - Acta Mycologica Sinica 8: 221-226.

[35] Xu, L., Tian, J. N., Wang, T., Li, L. B. (2017): Symbiosis established between orchid and Tulasnella spp. fungi. - Journal of Nuclear Agricultural Sciences 31: 876-883.

[36] Zhou, X., Gao, J. Y. (2016): Highly compatible Epa-01 strain promotes seed germination and protocorm development of Papilionanthe teres (Orchidaceae). - Plant Cell, Tissue and Organ Culture 125: 479-493.

[37] Zi, X. M., Sheng, C. L., Goodale, U. M., Shao, S. C., Gao, J. Y. (2014): In situ seed baiting to isolate germination-enhancing fungi for an epiphytic orchid, Dendrobium aphyllum (Orchidaceae). - Mycorrhiza 24: 487-499.

\section{APPENDIX}

Table A1. Effect of treatments, different days after seed sowing (20, 50 and 90 days) and photoperiod $(0 / 24 h L / D, 12 / 12 h L / D)$ on protocorm formation $(P F)$, seedling formation $(S F)$ and seedling development (SD) of D. catenatum was analysis by the Generalized Linear Model (GLM)

\begin{tabular}{|c|c|c|c|c|c|c|c|}
\hline \multicolumn{8}{|c|}{ Tests of between-subjects effects } \\
\hline Source & $\begin{array}{c}\text { Dependent } \\
\text { variable }\end{array}$ & $\begin{array}{l}\text { Type III sum } \\
\text { of squares }\end{array}$ & df & $\begin{array}{l}\text { Mean } \\
\text { square }\end{array}$ & $\mathbf{F}$ & Sig. & $\begin{array}{c}\text { Partial ETA } \\
\text { squared }\end{array}$ \\
\hline \multirow{3}{*}{ Corrected model } & PF & $66251.216^{\mathrm{a}}$ & 53 & 1250.023 & 6.534 & .000 & .715 \\
\hline & SF & $61084.418^{\mathrm{b}}$ & 53 & 1152.536 & 5.172 & .000 & .665 \\
\hline & SD & $16249.261^{\mathrm{c}}$ & 53 & 306.590 & 9.613 & .000 & .787 \\
\hline \multirow{3}{*}{ Intercept } & $\mathrm{PF}$ & 315286.495 & 1 & 315286.495 & 1648.148 & .000 & .923 \\
\hline & SF & 36025.433 & 1 & 36025.433 & 161.658 & .000 & .539 \\
\hline & SD & 1244.975 & 1 & 1244.975 & 39.037 & .000 & .221 \\
\hline \multirow{3}{*}{ Fungi } & $\mathrm{PF}$ & 42237.221 & 8 & 5279.653 & 27.599 & .000 & .615 \\
\hline & SF & 23516.125 & 8 & 2939.516 & 13.191 & .000 & .433 \\
\hline & SD & 2702.134 & 8 & 337.767 & 10.591 & .000 & .380 \\
\hline \multirow{3}{*}{ Days } & $\mathrm{PF}$ & 480.116 & 2 & 240.058 & 1.255 & .288 & .018 \\
\hline & SF & 7494.928 & 2 & 3747.464 & 16.816 & .000 & .196 \\
\hline & SD & 1463.664 & 2 & 731.832 & 22.947 & .000 & .250 \\
\hline \multirow{3}{*}{ Light } & $\mathrm{PF}$ & 10060.827 & 1 & 10060.827 & 52.593 & .000 & .276 \\
\hline & SF & 3980.068 & 1 & 3980.068 & 17.860 & .000 & .115 \\
\hline & SD & 1244.975 & 1 & 1244.975 & 39.037 & .000 & .221 \\
\hline \multirow{3}{*}{ Fungi $*$ days } & $\mathrm{PF}$ & 3738.838 & 16 & 233.677 & 1.222 & .259 & .124 \\
\hline & SF & 5652.889 & 16 & 353.306 & 1.585 & .080 & .155 \\
\hline & SD & 1854.342 & 16 & 115.896 & 3.634 & .000 & .296 \\
\hline \multirow{3}{*}{ Fungi $*$ light } & $\mathrm{PF}$ & 4659.075 & 8 & 582.384 & 3.044 & .003 & .150 \\
\hline & SF & 6176.256 & 8 & 772.032 & 3.464 & .001 & .167 \\
\hline & SD & 2702.134 & 8 & 337.767 & 10.591 & .000 & .380 \\
\hline \multirow{3}{*}{ Days * light } & $\mathrm{PF}$ & 254.811 & 2 & 127.406 & .666 & .515 & .010 \\
\hline & $\mathrm{SF}$ & 3892.707 & 2 & 1946.354 & 8.734 & .000 & .112 \\
\hline & SD & 1463.664 & 2 & 731.832 & 22.947 & .000 & .250 \\
\hline
\end{tabular}




\begin{tabular}{c|c|c|c|c|c|c|c}
\hline \multirow{2}{*}{$\begin{array}{c}\text { Fungi * days * } \\
\text { light }\end{array}$} & PF & 2678.830 & 16 & 167.427 & .875 & .599 & .092 \\
& SF & 4715.129 & 16 & 294.696 & 1.322 & .192 & .133 \\
& SD & 1854.342 & 16 & 115.896 & 3.634 & .000 & .296 \\
\hline \multirow{3}{*}{ Error } & PF & 26399.054 & 138 & 191.297 & & & \\
& SF & 30753.224 & 138 & 222.849 & & & \\
& SD & 4401.073 & 138 & 31.892 & & & \\
\hline \multirow{2}{*}{ Total } & PF & 461498.129 & 192 & & & & \\
& SF & 141339.060 & 192 & & & & \\
\hline \multirow{2}{*}{ Corrected total } & SD & 22848.824 & 192 & & & & \\
& PF & 92650.270 & 191 & & & & \\
\hline
\end{tabular}

${ }^{\mathrm{a}} \mathrm{R}$ Squared $=.715$ (Adjusted R Squared $=.606$ )

${ }^{\mathrm{b}} \mathrm{R}$ Squared $=.665$ (Adjusted R Squared $\left.=.537\right)$

${ }^{\mathrm{c}} \mathrm{R}$ Squared $=.787$ (Adjusted R Squared $=.705$ )

Table A2. Effects of days after seed sowing (20 days) on protocorm formation, seedling formation and seedling development of $D$. catenatum

\begin{tabular}{|c|c|c|c|c|c|c|}
\hline \multicolumn{7}{|c|}{ ANOVA } \\
\hline & & Sum of squares & df & Mean square & $\mathbf{F}$ & Sig. \\
\hline \multirow{3}{*}{ PF } & Between groups & 17862.897 & 8 & 2232.862 & 8.053 & .000 \\
\hline & Within groups & 13586.390 & 49 & 277.273 & & \\
\hline & Total & 31449.288 & 57 & & & \\
\hline \multirow{3}{*}{ SF } & Between groups & 8735.217 & 8 & 1091.902 & 43.151 & .000 \\
\hline & Within groups & 1239.895 & 49 & 25.304 & & \\
\hline & Total & 9975.113 & 57 & & & \\
\hline \multirow{3}{*}{ SD } & Between groups & .000 & 8 & .000 & . & . \\
\hline & Within groups & .000 & 49 & .000 & & \\
\hline & Total & .000 & 57 & & & \\
\hline
\end{tabular}

Table A3. Effects of days after seed sowing (50 days) on protocorm formation, seedling formation and seedling development of D. catenatum

\begin{tabular}{|c|c|c|c|c|c|c|}
\hline \multicolumn{7}{|c|}{ ANOVA } \\
\hline & & Sum of squares & df & Mean square & $\mathbf{F}$ & Sig. \\
\hline \multirow{3}{*}{ PF } & Between groups & 14183.535 & 8 & 1772.942 & 5.443 & .000 \\
\hline & Within groups & 17588.268 & 54 & 325.709 & & \\
\hline & Total & 31771.803 & 62 & & & \\
\hline \multirow{3}{*}{$\mathrm{SF}$} & Between groups & 11474.560 & 8 & 1434.320 & 4.176 & .001 \\
\hline & Within groups & 18545.377 & 54 & 343.433 & & \\
\hline & Total & 30019.936 & 62 & & & \\
\hline \multirow{3}{*}{ SD } & Between groups & 1239.046 & 8 & 154.881 & 4.984 & .000 \\
\hline & Within groups & 1678.045 & 54 & 31.075 & & \\
\hline & Total & 2917.091 & 62 & & & \\
\hline
\end{tabular}


Table A4. Effects of days after seed sowing (90 days) on protocorm formation, seedling formation and seedling development of D. catenatum

\begin{tabular}{|c|c|c|c|c|c|c|}
\hline \multicolumn{7}{|c|}{ ANOVA } \\
\hline & & Sum of squares & df & Mean square & $\mathbf{F}$ & Sig. \\
\hline \multirow{3}{*}{ PF } & Between groups & 16241.252 & 8 & 2030.157 & 9.699 & .000 \\
\hline & Within groups & 12977.528 & 62 & 209.315 & & \\
\hline & Total & 29218.781 & 70 & & & \\
\hline \multirow{3}{*}{ SF } & Between groups & 8578.690 & 8 & 1072.336 & 2.098 & .049 \\
\hline & Within groups & 31687.926 & 62 & 511.096 & & \\
\hline & Total & 40266.616 & 70 & & & \\
\hline \multirow{3}{*}{ SD } & Between groups & 5104.227 & 8 & 638.028 & 3.804 & .001 \\
\hline & Within groups & 10397.796 & 62 & 167.706 & & \\
\hline & Total & 15502.023 & 70 & & & \\
\hline
\end{tabular}

Table A5. Effect of fungal inoculation treatments on the growth formation of protocorm, seedling and seedling development of the species D. catenatum under in vitro conditions

\begin{tabular}{c|c|c|c|c|c|c}
\hline \multicolumn{7}{c}{ ANOVA } \\
\hline \multirow{4}{*}{ PF } & Sum of squares & df & Mean square & F & Sig. \\
\hline \multirow{4}{*}{ SF } & Within groups & 44342.513 & 8 & 5542.814 & 20.997 & .000 \\
& Total & 92607.757 & 183 & 263.977 & & \\
& Between groups & 23707.942 & 191 & & & \\
& Within groups & 68129.700 & 183 & 372.293 & & .000 \\
& Total & 91837.642 & 191 & & & \\
\hline \multirow{3}{*}{ SD } & Between groups & 3860.007 & 8 & 482.501 & 5.259 & .000 \\
& Within groups & 16790.327 & 183 & 91.750 & & \\
& Total & 20650.334 & 191 & & & \\
\hline
\end{tabular}

